\title{
FAKTOR-FAKTOR YANG DIPERTIMBANGKAN KONSUMEN MENGGUNAKAN JASA BENGKEL MOBIL "SINAR KARYA" DI KOTA PALU
}

\author{
BUSTANUL HAQ \\ JOHNNY TANAMAL \\ NIRWAN \\ Program Studi Manajemen, Fakultas Ekonomi, Universitas Tadulako \\ Email: bustanulhaq15@gmail.com,nirwan.fe.untad@gmail.com
}

\begin{abstract}
This study aims to describe the factors that consumers consider using the "Sinar Karya" Car Repair Service in Palu City. The problems raised in this study are what factors are considered by consumers using the services of the "Sinar Karya" Car Repair Shop in Palu City. The sample of this study were 96 respondents, namely consumers who use the services of "Sinar Karya" Car Repair Shop in Palu City. This study uses explorative research type, using data collection methods in the form of observation, interviews, documentation, questionnaires and literature study. Instrument testing uses validity and reliability tests. The results of factor analysis that consumers consider using the "Sinar Karya" Car Repair Service in Palu City concludes that there are 4 (four) factors that consumers consider using the "Sinar Karya" Car Repair Service in Palu City. The four factors are the factors of people and service, place factors, proximity factors, and characteristic factors. Overall, the four factors mentioned, have been empirically proven are the factors that are considered by consumers using the Motorbike's "Sinar Karya" Car Repair Service in the City of Palu

Keywords: Factors considered by consumers, "Sinar Karya" Car Workshop
\end{abstract}

\begin{abstract}
ABSTRAK
Penelitian ini bertujuan untuk mendeskripsikan faktor-faktor yang dipertimbangkan konsumen menggunakan jasa Bengkel Mobil "Sinar Karya" di Kota Palu. Permasalahan yang dikemukakan dalam peneitian ini adalah faktor-faktor apakah yang dipertimbangkan konsumen menggunakan jasa Bengkel Mobil "Sinar Karya" di Kota Palu. Sampel penelitian ini sebanyak 96 responden, yaitu konsumen yang menggunakan jasa Bengkel Mobil "Sinar Karya" di Kota Palu. Penelitian ini menggunakan tipe penelitian explorative, dengan menggunakan metode pengumpulan data berupa observasi, wawancara, dokumentasi, kuesioner dan studi kepustakaan. Pengujian instrument menggunakan uji validitas dan uji reabilitas. Hasil analisis faktor yang dipertimbangkan konsumen menggunakan jasa Bengkel Mobil "Sinar Karya" di Kota Palu menyimpulkan bahwa terdapat 4 (empat) faktor yang dipertimbangkan konsumen menggunakan jasa Bengkel Mobil "Sinar Karya" di Kota Palu. Keempat faktor tersebut adalah Faktor people dan pelayanan, faktor tempat (place), faktor hubungan kedekatan, dan faktor karakteristik. Secara keseluruhan keempat faktor ditersebut, telah terbukti secara empiris merupakan faktor-faktor yang dipertimbangkan konsumen menggunakan jasa Bengkel Mobil "Sinar Karya" Motor di Kota Palu.
\end{abstract}

Kata Kunci: Faktor yang dipertimbangkan konsumen, Bengkel Mobil "Sinar Karya"

\section{PENDAHULUAN}

Perkembangan yang semakin pesat dibidang otomotif selama beberapa tahun belakangan ini, membuat persaingan antara produk-produk kendaraan roda empat, baik dalam hal bentuk, jenis dan merek yang beraneka ragam dengan spesifikasi masing-masing dari produk tersebut. Inovasi produk pun semakin berkembang dengan tujuan untuk memberikan kepuasan kepada para konsumen serta menjaga agar konsumen tetap setia pada produk maupun jasa yang ditawarkan, berbagai kemudahan pun terus 
dikembangkan guna memudahkan para konsumen untuk memperoleh atau mendapatkan produk maupun jasa yang ditawarkan, seperti pembelian secara kredit, garansi, serta menjamin ketersediaan suku cadang.

Bengkel Mobil "Sinar Karya" adalah bengkel yang bergerak dalam bidang jasa yang terletak di Jl. Sungai Sa'dan, Kelurahan Nunu. Bengkel ini mengkhususkan diri melayani body repair mobil car painting dengan didukung oleh tenaga ahli yang sudah berpengalaman dibidangnya. Body repair mobil yang ditawarkan antara lain seperti: perbaikan mobil penyok, kropos ataupun lecet, ketok, poles perbaikan body penyok berat maupun ringan, cat body siram, ganti warna mobil, pendempulan, cat body restorasi, sol cat, dll. Selain itu untuk mendapatkan pengguna jasanya bengkel ini juga bekerja sama dengan pihak Asuransi dengan tujuan untuk mendapatkan keuntungan satu sama lain.

\section{Pengguna Bengkel Mobil "Sinar Karya"} di Kota Palu Tahun 2013-2017

\begin{tabular}{|c|c|c|c|}
\hline No & Tahun & Pengguna Jasa & Persentase (\%) \\
\hline 1 & 2013 & 827 & $6.77 \%$ \\
\hline 2 & 2014 & 883 & $5.88 \%$ \\
\hline 3 & 2015 & 935 & $5.13 \%$ \\
\hline 4 & 2016 & 983 & $4.37 \%$ \\
\hline 5 & 2017 & 1026 & - \\
\hline
\end{tabular}

Sumber: Data diolah Tahun 2018

Pengguna bengkel Mobil "Sinar Karya" di Kota Palu mengalami kesenjangan yang seharusnya jika setiap tahunnya pengguna bengkel mengalami kenaikan maka persentase juga harus naik, namun dalam hal ini persentase yang terjadi pada pengguna bengkel ini menurun setiap tahunnya.

Berdasarkan hal tersebut penulis merasa penting untuk melakukan penelitian tentang faktor-faktor yang dipertimbangkan konsumen menggunakan jasa Bengkel Mobil "Sinar Karya" di Kota Palu. Namun sebelumnya, penulis melakukan pra penelitian dengan meminta 11 responden dengan kriteria berusia 17 tahun ke atas dan minimal (dua) kali menggunakan jasa bengkel tersebut, kemudian responden mengajukan pendapatnya mengenai fakotor-faktor yang dipertimbangkan konsumen menggunakan jasa Bengkel Mobil "Sinar Karya" di Kota Palu. Hasilnya terdapat 17 faktor yang dipertimbangkan konsumen menggunakan jasa Bengkel Mobil "Sinar Karya" di Kota Palu.

Faktor-Faktor Yang Dipertimbangkan Konsumen Menggunakan Jasa Bengkel Mobil "Sinar Karya" di Kota Palu

\begin{tabular}{|l|l|}
\hline No & Faktor-faktor yang dipertimbangkan \\
\hline 1 & Bengkel sudah dikenal \\
\hline 2 & Lokasi bengkel mudah dijangkau \\
\hline 3 & Perlatan bengkel lengkap \\
\hline 4 & Menjaga kebersihan lingkungan kerja \\
\hline 5 & Pilihan cat bervariasi dan sesuai pesanan \\
\hline 6 & Menggunakan sistem kendali dengan tekhnologi IT \\
\hline 7 & Biaya servis terjangkau \\
\hline
\end{tabular}


JURNAL ILMU MANAJEMEN UNIVERSITAS TADULAKO

Vol. 5, No. 3, September 2019, p. 228 - 239

ISSN : 2443-3578 (On Line) / ISSN : 2443-1850 (Print)

\begin{tabular}{|l|l|}
\hline 8 & Menyambut kedatangan konsumen ketika servis \\
\hline 9 & Hubungan baik dengan karyawan bengkel \\
\hline 10 & Pelayanan karyawan bengkel yang sopan dan ramah \\
\hline 11 & Pelayanan karyawan bengkel yang cepat dan tepat \\
\hline 12 & Mendengar saran dari teman \\
\hline 13 & Kesediaan melayani kembali, pasca servis \\
\hline 14 & Mendiskusikan kerusakan mobil \\
\hline 15 & Senantiasa menggunakan evaluasi kinerja \\
\hline 16 & Dapat melakukan modifikasi sesuai dengan pesanan pelanggan \\
\hline 17 & Kepuasan setelah menggunakan jasa \\
\hline
\end{tabular}

Sumber: Data Primer (Data diolah penulis dari kuesioner)

Berdasarkaan pada fenomena-fenomena serta hasil observasi dan wawancara di atas, maka penulis tertarik untuk melakukan penelitian dengan judul "faktor-faktor yang dipertimbangkan konsumen menggunakan jasa Bengkel Mobil "Sinar Karya" di Kota Palu".

\section{KAJIAN LITERATURE DAN PENGEMBANGAN HIPOTESIS}

Pemasaran adalah mengetahui dan memahamipelanggan dengan baik sehingga produk atau jasa Kotler dan Keller (2009:5), pemasaran secara sosial adalah sebuah proses kemasyarakatan di mana individu dan kelompok memperoleh apa yang mereka butuhkan dan inginkan dengan menciptakan, menawarkan, dan secara bebas mempertukarkan produk dan jasa yang bernilai dengan orang lain. Tujuan bias sesuai dengan kebutuhannya sehingga terjual sendiri (Kotler dan Keller,2009:6). Pemasaran adalah proses mengidentifikasi, menciptakandan mengkomunikasikan nilai, serta memelihara hubungan yang memuaskan pelanggan untuk memaksimalkan keuntungan perusahaan (Hasan, 2013:4).

Manajemen pemasaran memiliki peran yang krusial dalam sebuah perusahaan, karena manajemen pemasaran mengatur seluruh kegiatan pemasaran. Kotler dan Keller (2009:5), manajemen pemasaran (marketing management) adalah seni dan ilmu memilih pasar sasaran dan meraih, mempertahankan, serta menumbuhkan pelanggan dengan menciptakan, menghantarkan, dan mengkomunikasikan nilai pelanggan yang unggul. Tjiptono (2011:2), manajemen pemasaran merupakan sistem total aktivitas bisnis yang dirancang untuk merencanakan, menetapkan harga, dan mendistribusikan produk, jasa dan gagasan yang mampu memuaskan keinginan pasar sasaran dalam rangka mencapai tujuan organisasional.

Jasa bukan suatu barang, melainkan suatu proses atau aktivitas yang tidak berwujud. Di dalam jasa selalu ada aspek interaksi antara pihak konsumen dan pihak produsen (jasa), meskipun pihak-pihak yang terlibat tidak selalu menyadari. Secara umum jasa adalah pemberian suatu kinerja atau tindakan tak kasar mata dan satu pihak kepada pihak lain. Pada umumnya jasa diproduksi dan dikonsumsi secara bersamaan, di mana interaksi antara pemberi jasa dan penerima jasa mempengaruhi hasil jasa tersebut.

Kotler dan Keller (2009:36), jasa/layanan (servis) adalah semua tindakan atau kinerja yang dapat ditawarkan satu pihak kepada pihak lain yang pada intinya tidak berwujud dan tidak menghasilkan kepemilikan apapun. Tjiptono (2014:26), mengemukakan jasa sebagai setiap tindakan atau perbuatan yang 
dapat ditawarkan oleh suau pihak lain yang pada dasarnya bersifat intangible (tidak berwujud fisik) dan tidak menghasilkan kepemilikan sesuatu.

Mursid (2010:116), mendefinisikan bahwa jasa adalah kegiatan yang dapat diidentifikasi secara tersendiri, pada hakikatnya bersifat tidak teraba, untuk memenuhi kebutuhan dan tidak harus terikat pada penjualan produsen atau jasa lain. Berdasarkan definisi di atas, jasa bukan merupakan barang, juga jasa merupakan suatu proses atau aktivitas, dan aktivitas-aktivitas tersebut tidak berwujud. Oleh karena itu kata lain jasa pada dasarnya adalah sesuatu yang tidak dapat diraba, dan disentuh tetapi memberikan nilai tambah.

Seperti halnya produk, jasa juga memiliki karakteristik atau ciri khas yang harus diperhatiakan karena karakteristik ini akan mempengaruhi dalam pengembangan strategi pemasaran. Kotler \& Keller (2009:39), ada empat karakteristik utama yang sangat mempengaruhi desain program pemasaran. Keempat karakteristik tersebut meliputi: (1) Tidak berwujud (intangible) Tidak seperti produk fisik, jasa tidak dapat dilihat, dirasa, diraba, didengar, atau dibaui sebelum jasa itu dibeli. Untuk mengurangi ketidakpastian, pembeli akan mencari bukti kualitas dengan mengambil kesimpulan dari tempat, orang, peralatan, bahan komunikasi, symbol, dan harga. Karena itu, tugas penyedia jasa adalah "mengelola bukti", untuk "mewujudkan hal yang tidak berwujud". (2) Tidak terpisahkan (inseparability) Sementara barang fisik dibuat, dimasukan dalam persediaan, didistribusikan melalui berbagai perantara, dan dikonsumsi kemudian, jasa umumnya diproduksi dan dikonsumsi sekaligus. (3) Bervariasi (variability)Karena kualitas jasa tergantung pada siapa yang menyediakannya, kapan dan dimana, dan kepada siapa, jasa sangat bervariasi.(a) Berinvestasi dalam prosedur ketenaga kerjaan dan pelatihan yang baik. (b) Menstandarisasikan proses kinerja jasa di seluruh organisasi. (c) Mengamati kepuasaan pelanggan. (4) Dapat Musnah (perishability)Jasa tidak dapat disimpan, jadi dapat musnahnya jasa bisa menjadi masalah ketika permintaan berfluktuasi. Jasa yang tepat harus disediakan untuk pelanggan yang tepat pada tempat yang tepat disaat yang tepat dan harga yang tepat untuk memaksimalkan profitabilitas.

Setiadi (2015:2), perilaku konsumen adalah tindakan yang langsung terlibat dalam mendapatkan, mengonsumsi dan menghabiskan produk atau jasa, termasuk proses keputusan yang mendahului dan menyusuli tindakan ini. Kotler dan Keller (2009:166), perilaku konsumen adalah studi tentang bagaimana individu, kelompok dan organisasi memilih, membeli, menggunakan, dan bagaimana barang, jasa, ide, atau pengalaman untuk memuaskan kebutuhanan dan keinginan mereka.

Sumarwan (2011:5), menyatakan perilaku konsumen adalah semua kegiatan, tindakan, serta proses psikologis yang mendorong tindakan tersebut pada saat sebelum membeli, menggunakan, dan menghabiskan produk dan jasa setelah melakukan hal-hal di atas atau kegiatan evaluasi. Perilaku konsumen adalah studi proses yang terlibat ketika individu atau kelompok memilih, membeli, menggunakan, atau mengatur produk, jasa, idea atau pengalaman untuk memuaskan kebutuhan dan keinginan konsumen (Hasan, 2013:161).

Keputusan pembelian konsumen merupakan bagian utama dari perilaku konsumen yang tidak dapat dipisahkan sebelum menetapkan keputusan untuk mengggunakan atau tidak menggunakan produk yang ditawarkan perusahaan. Kotler dan Keller (2009:1114), menyatakan bahwa pengambilan keputusan pembelian konsumen terdiri dari lima tahap, yaitu:

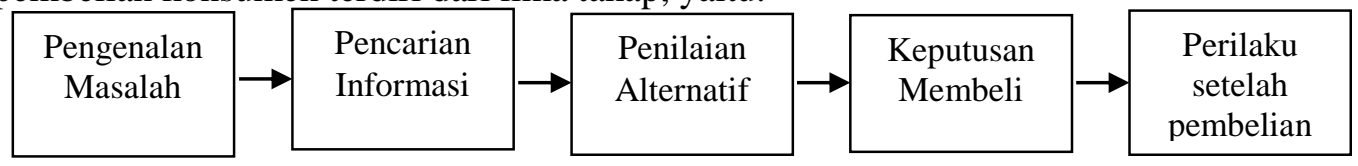

Pengertian bengkel secara umum tempat (bangunan atau ruangan) untuk perawatan/pemeliharaan, perbaikan, modifikasi alat dan mesin (alsin), tempat pembuatan bagian mesin dan perakitan alsin. Bengkel memiliki arti tempat memperbaiki mobil, sepeda, dsb. Bengkel otomotif adalah tempat dimana kendaraan diperbaiki oleh teknisi atau tenaga mekanik. Bengkel repair shop melakukan pekerjaan seperti perbaikan mesin kendaraan, rem, knalpot, transmisi, ban, kaca mobil dan penggantian oli. Bengkel body shop 
melakukan pekerjaan seperti perbaikan cat terhadap goresan, lecet, dan penyok terhadap kerusakan kendaraan serta kerusakan yang disebabkan oleh tabrakan dan kecelakaan besar.

Secara umum fungsi bengkel adalah melayani kerperluan teknis dari para pelanggannya. Ini berarti bahwa perbaikan kendaraan adalah tugas sebuah bengkel dan hanya berlangsung jika pelanggan menemui kesulitan dengan kendaraannya. Untuk itu sistem dan administrasi bengkel diarahkan kepada organisasi dan fasilitas yang dapat memperlancar pekerjaan-pekerjaan teknis dibengkel secara internal.

\section{METODE PENELITIAN}

Tipe penelitian yaitu penelitian eksploratif (explorative research) Malhotra (2005:91), tujuan riset eksploratif adalah untuk mengeksplorasi atau mencari masalah atau situasi untuk mendapatkan wawasan dan pemahaman. Oleh karena itu tipe penelitian ini diharapkan dapat memperoleh pemahaman yang mendalam dan pemikiran-pemikiran baru dalam memecahkan masalah yang ada dalam masalah sebuah penelitian.

Objek dalam penelitian ini adalah faktor-faktor yang dipertimbankan kosumen menggunakan jasa Bengkel Mobil "Sinar Karya” di Kota Palu.

Subjek dalam penelitian ini dilakukan pada masyarakat Kota Palu yang menggunakan jasa Bengkel Mobil "Sinar Karya" dengan pertimbangan faktor-faktor yang dipertimbangkan konsumen menggunakan jasa bengkel tersebut. Lokasi penelitian Jl. Sungai Sa'dan, Kelurahan Nunu.

Data yang dikumpulkan harus dapat dibuktikan kebenarannya, tepat waktu, sesuai dan dapat memberikan gambaran yang menyeluruh. Maka jenis data yang diguakan dalam penelitian ini adalah: (1) Data Kuantitatif: Digunakan untuk meneliti pada populasi atau sampel tertentu, teknik pengambilan sampel pada umumnya dilakukan secara random, pengumpulan data menggunakan instrumen penelitian, analisis data bersifat kuantitatif/statistik dengan tujuan untuk menguji hipotesis yang telah ditetapkan. (2) Data Kualitatif: Digunakan untuk meneliti keadaan yang alamiah, (sebagai lawannya adalah experiment) dimana peneliti sebagai instrument kunci, pengambilan sampel sumber data dilakukan secara purposive dan snowbal, teknik pengumpulan dengan trianggulasi (gabungan).

Sumber data yang digunakan dalam penelitian ini adalah: (1) Data Primer: Data Primer diperoleh secara langsung dari objek yang diteliti, atau hubungannya dengan yang diteliti yaitu berupa hasil wawancara langsung dan jawaban responden terhadap kuesioner tentang faktor-faktor yang dipertimbangkan konsumen menggunakan menggunakan jasa Bengkel Mobil "Sinar Karya" di Kota Palu. (2) Data sekunder: Data sekunder adalah data yang tidak langsung dan diperoleh dari berbagai sumber pustaka seperti sumber buku, jurnal dan dokumen-dokumen dari pihak yang terkait mengenai masalah faktor-faktor yang dipertimbankan kosumen menggunakan jasa Bengkel Mobil "Sinar Karya" di Kota Palu.

Teknik pengumpulan data merupakan langkah yang paling utama dalam penelitian, karena tujuan utama dari penelitian adalah mendapatkan data. Tanpa mengetahui teknik pengumpulan data, maka peneliti tidak akan mendapatkan data yang memenuhi standar data yang ditetapkan. Adapun teknik pengumpulan data yang digunakan dalam penelitian ini: (1) Pengamatan/Observasi: Observasi dilakukan dengan cara menanyakan langsung kepada pemilik bengkel tentang data pengguna jasa Bengkel Mobil "Sinar Karya" di Kota Palu. (2) Dokumentasi: Husein Umar (2013:30), menyatakan bahwa dokumentasi merupakan pengumpulan data yang dilakukan dengan menelaah dokumen-dokumen yang terdapat pada perusahaan. (3) Kuesioner yang dibagikan secara langsung oleh penulis kepada responden yang ditemui secara langsung di lokasi penelitian. (4) Studi kepustakaan: Merupakan teknik pengumpulan data dengan cara membaca dan mengamati, mengolah laporan-laporan serta catatan yang menunjang penelitian ini.

Populasi dalam penelitian ini adalah masyarakat Kota Palu yang menggunakan jasa Bengkel Mobil "Sinar Karya". Berdasarkan data pengguna jasa bengkel tersebut untuk tahun 2017 sebanyak 1026 
pengguna. Namun demikian jumlah tersebut tidak bias dijadikan sebagai data besarnya populasi, karena jumlah tersebut terdapat perhitungan ganda untuk setiap penggunanya.

Sampel dalam penelitian ini adalah seluruh masyarakat Kota Palu yang menggunakan jasa Bengkel "Sinar Karya". Besarnya sampel dalam penelitian ini ditentukan dengan menggunakan rumus Widiyanto (2012:58) yaitu:

$$
\mathbf{n}=\frac{\mathbf{Z}^{2}}{4(\text { Moe })^{2}}
$$

\section{Keterangan:}

$$
\begin{array}{lll}
\mathrm{n} & = & \text { Jumlah Sampel } \\
\mathrm{Z} & = & \text { Skor pada tingat signifikansi tertentu (95\%) maka } \mathrm{Z}=1.96 \\
\mathrm{e} & = & \text { Margin of error, tingkat kesalahan maksimum adalah } 10 \%
\end{array}
$$

Setelah menggunakan rumus diatas, maka diperoleh perhitungan sebagai berikut:

$$
\mathrm{n}=\frac{(1.96)^{2}}{4(10 \%)^{2}} \quad=96.04 \text { dibulatkan menjadi } 96 \text { orang }
$$

Terlihat pada penjelasan rumus di atas maka diperoleh jumlah sampel yang diambil dalam penelitian ini adalah sebanyak 96 responden. Pemilihan sampel dilakukan dengan menggunakan metode purposive sampling, yaitu teknik penentuan sampel dengan pertimbangan tertentu.

Operasional variabel adalah penentuan konstrak atau sifat yang akan dipelajari sehingga menjadi variabel yang dapat diukur. Dalam penelitian ini terdapat 17 faktor-faktor yang diajukan untuk mengetahui faktor-faktor yang dipertimbangkan konsumen menggunakan Bengkel Mobil "Sinar Karya" di Kota Palu.

Pada metode analisis ini, yang dianalisis adalah faktor-faktor yang dipertimbangkan konsumen menggunakan jasa Bengkel Mobil "Sinar Karya". Untuk itu dalam menguji hipotetis penelitian ini menggunakan metode analisis kualitatif dalam bentuk pemaparan hasil analisis data penelitian dan metode kuantitatif dalam bentuk pemaparan melalui hasil perhitungan angka-angka statistik dengan alat statistik analisis faktor (factor analysis). Malhotra (2005:619), menyatakan bahwa analisis faktor adalah sekelompok prosedur atau metode yang dipake untuk mengurangi atau meringkas data. Secara sistematif analisis faktor data disajikan sebagai berikut:

\section{$\mathrm{Xi}=\mathrm{Ai1} . \mathrm{F1}+\mathrm{Ai2} . \mathrm{F2}+\mathrm{Ai3.F3}+\ldots . .+\mathrm{Aij} . \mathrm{Fm}+\mathrm{Vi} . \mathrm{Ui}$}

Keterangan:

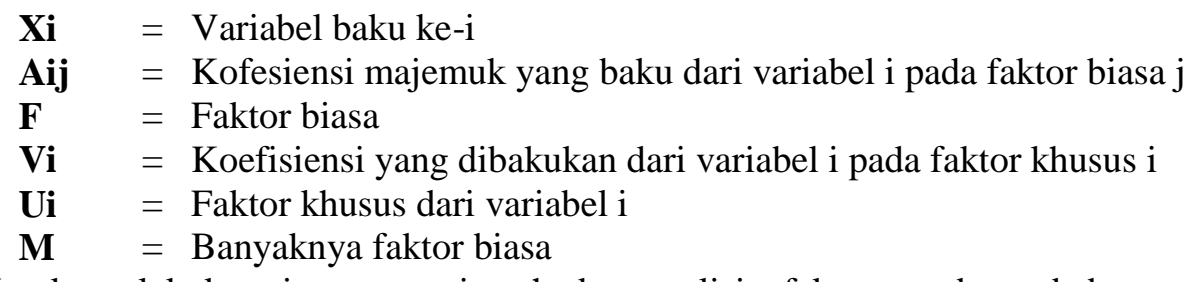

Untuk melakukan interprestasi terhadap analisis faktor, terdapat beberapa konsep statistik yang berhubungan dengan penelitian pembuktian hipotetis pertama. 


\section{HASIL DAN PEMBAHASAN}

Hasil penelitian ini membahas karakteristik responden, dan hasil pengujian instrument penelitian (uji validitas dan uji reliabilitas) serta diuji menggunakan metode analisis faktor. Uji instrumen dalam penelitian ini menggunakan 96 sampel dan akan diuji sejauh mana alat pengukur yang dipergunakan untuk mengukur apa yang akan diukur. Pengujian instrument ini menggunakan program SPSS 16 For Windows.

Uji validitas dalam penelitian ini menggunakan bantuan perangkat lunak komputer (software) program SPSS Versi 16.0 For Windows. Uji validitas digunakan untuk mengukur sah atau valid tidaknya suatu kuesioner. Sugiyono (2015:183), menyatakan syarat minimum untuk dianggap memenuhi syarat adalah $\mathrm{r}=0.3$. Untuk lebih jelasnya hasil uji validitas yang diperoleh dari setiap item pernyataan dapat dilihat pada tabel berikut:

\section{Hasil Uji Validitas Instrumen Penelitian}

\begin{tabular}{|c|c|c|c|}
\hline $\begin{array}{c}\text { Faktor yang } \\
\text { dipertimbangkan }\end{array}$ & $\begin{array}{c}\text { Corrected Item-Total } \\
\text { Correlation }\end{array}$ & r-kritis & Ket \\
\hline X1 & 0.374 & 0.30 & Valid \\
\hline X2 & 0.312 & 0.30 & Valid \\
\hline X3 & 0.497 & 0.30 & Valid \\
\hline X4 5 & 0.304 & 0.30 & Valid \\
\hline X6 & 0.467 & 0.30 & Valid \\
\hline X7 & 0.426 & 0.30 & Valid \\
\hline X8 & 0.504 & 0.30 & Valid \\
\hline X9 & 0.364 & 0.30 & Valid \\
\hline X10 & 0.523 & 0.30 & Valid \\
\hline X11 & 0.433 & 0.30 & Valid \\
\hline X12 & 0.389 & 0.30 & Valid \\
\hline X13 & 0.401 & 0.30 & Valid \\
\hline X14 & 0.301 & 0.30 & Valid \\
\hline X15 & 0.341 & 0.30 & Valid \\
\hline X16 & 0.496 & 0.30 & Valid \\
\hline X17 & 0.375 & 0.30 & Valid \\
\hline
\end{tabular}

Sumber: Data diolah Tahun 2018

Dapat dilihat bahwa semua faktor yang dipertimbangkan konsumen menggunakan jasa dianggap valid. Hal ini dikarenakan nilai Corrected Item-Total Correlation > r-kritis.

Uji reliabilitas dalam penelitian ini menggunakan bantuan perangkat lunak komputer (software) program SPSS Versi 16.0 For Windows, Hasil dari pengujian ini, peneliti mengukur reliabelnya suatu variabel dengan cara melihat Cronbach Alpha dengan signifikansi yang digunakan lebih besar dari 0.70. Untuk lebih jelasnya hasil uji realibilitas yang diperoleh dari setiap item pernyataan dapat dilihat pada tabel berikut:

Hasil Uji Reliabilitas Instrument Penelitian

\begin{tabular}{|c|c|c|c|}
\hline $\begin{array}{c}\text { Faktor yang } \\
\text { dipertimbangkan }\end{array}$ & $\begin{array}{c}\text { Cronbach's Alpha If } \\
\text { Item Deleted }\end{array}$ & r-kritis & Ket \\
\hline $\mathrm{X} 1$ & 0.768 & 0.70 & Reliabel \\
\hline $\mathrm{X} 2$ & 0.781 & 0.70 & Reliabel \\
\hline $\mathrm{X} 3$ & 0.757 & 0.70 & Reliabel \\
\hline $\mathrm{X} 4$ & 0.783 & 0.70 & Reliabel \\
\hline \multicolumn{3}{|l}{} \\
\hline
\end{tabular}


JURNAL ILMU MANAJEMEN UNIVERSITAS TADULAKO

Vol. 5, No. 3, September 2019, p. 228 - 239

ISSN : 2443-3578 (On Line) / ISSN : 2443-1850 (Print)

\begin{tabular}{|c|c|c|c|}
\hline X5 & 0.762 & 0.70 & Reliabel \\
\hline X6 & 0.766 & 0.70 & Reliabel \\
\hline X7 & 0.766 & 0.70 & Reliabel \\
\hline X8 & 0.772 & 0.70 & Reliabel \\
\hline X9 10 & 0.759 & 0.70 & Reliabel \\
\hline X11 & 0.763 & 0.70 & Reliabel \\
\hline X12 & 0.769 & 0.70 & Reliabel \\
\hline X13 & 0.766 & 0.70 & Reliabel \\
\hline X14 & 0.773 & 0.70 & Reliabel \\
\hline X15 & 0.770 & 0.70 & Reliabel \\
\hline X16 & 0.766 & 0.70 & Reliabel \\
\hline X17 & 0.769 & 0.70 & Reliabel \\
\hline
\end{tabular}

Sumber: Data diolah Tahun 2018

Berdasarkan hasil pengujian realiabilitas pada tabel di atas, diketahui bahwa bahwa semua faktor yang dipertimbangkan konsumen menggunakan jasa dianggap reliabel, karena semua faktor yang dipertimbangkan memiliki nilai Alpha lebih besar atau sama dengan $0.70(\alpha \geq 0.70)$.

Tahap pertama pada analisis faktor adalah menilai mana saja variabel yang dianggap layak (appropriateness) untuk dimasukan ke dalam analisis selanjutnya.

Hasil pengujian analisis faktor tahap pertama pada 17 faktor yang dipertimbangkan konsumen menggunakan jasa Bengkel Mobil "Sinar Karya" di Kota Palu dengan bantuan komputer program statistik SPSS Versi 16.0 For Windows. Dapat dilihat pada nilai KMO and Bartlett's Test pada tabel berikut ini:

KMO and Bartlett's Test

\begin{tabular}{|c|c|c|}
\hline \multicolumn{3}{|c|}{ KMO and Bartlett's Test } \\
\hline \multicolumn{2}{|c|}{ Kaiser-Meyer-Olkin Measure of Sampling Adequacy. } & .693 \\
\hline \multirow[t]{3}{*}{ Bartlett's Test of Sphericity } & Approx. Chi-Square & 478.852 \\
\hline & Df & 136 \\
\hline & Sig. & .000 \\
\hline
\end{tabular}

Berdasarkan tabel di atas, terlihat nilai KMO Measure of Sampling Adequacy (MSA) sebesar 0.693 dengan signifikan (0.000). Karena angka MSA berada di atas angka $0.5(>0.5)$, maka variabel yang ada dapat dianalisis lebih lanjut. Selanjutnya setiap variabel dianalisis untuk mengetahui mana yang dapat diperoses lebih lanjut dan mana yang harus dikeluarkan.

Setelah melalui dan menyelesaikan tahap pertama, maka pada tahap ini dilakukan lagi pengujian analisis faktor dengan melibatkan variabel-variabe yang memenuhi persyaratan pada pengolahan data. Analisis faktor pada tahap ini melibatkan 15 variabel penelitian untuk mengetahui berapa banyak faktor yang terbentuk dari variabel-variabel tersebut.

Hasil pengujian analisis faktor tahap kedua melibatkan 15 faktor yang dipertimbangkan konsumen menggunakan jasa Bengkel Mobil "Sinar Karya" di Kota Palu dengan bantuan komputer program statistik SPSS Versi 16.0 For Windows. Dapat dilihat pada nilai KMO and Bartlett's Test pada Tabel berikut ini 


\section{KMO and Bartlett's Test}

\begin{tabular}{|l|l|r|}
\hline Kaiser-Meyer-Olkin Measure of Sampling Adequacy. & .698 \\
\hline \multirow{3}{*}{ Bartlett's Test of Sphericity } & Approx. Chi-Square & 405.673 \\
\cline { 2 - 3 } & Df & 105 \\
\cline { 2 - 3 } & Sig. & .000 \\
\hline
\end{tabular}

Berdasarkan tabel di atas, terlihat nilai KMO Measure of Sampling Adequacy (MSA) sebesar 0.698 dengan signifikan (0.000). Karena angka MSA berada di atas angka $0.5(>0.5)$, maka variabel yang ada dapat dianalisis lebih lanjut. Oleh karena itu angka ini menunjukkan bahwa model ini memiliki kecocokan (Fit) yang tinggi.

Pada tabel Anti Image Correlation, khusunya pada angka korelasi yang bertanda "a" (arah diagonal dari kiri atas ke kanan bawah) yang menggambarkan besaran MSA setiap variabel. Hal ini dilakukan untuk memastikan bahwa tidak terdapat variabel yang memiliki angka MSA di bawah $0.5(<0.5)$. Berdasarkan hasil pengujian pada tahap kedua ini, tidak dijumpai satupun variabel penelitian yang mempunyai angka MSA di bawah 0.5, dengan demikian, maka tidak terdapat maasalah ada tahap ini dan pengujian dapat dilanjutkan.

Tahap selanjutnya tabel Communalities. Communalities pada dasarnya adalah jumlah varians dari suatu variabel mula-mula yang bisa dijelaskan oleh faktor yang ada. Untuk lebih jelasnya dapat dilihat pada tabel berikut ini:

Tabel

\section{Communalities}

\begin{tabular}{|l|r|r|}
\hline \multicolumn{3}{|c|}{ Communalities } \\
\hline & Initial & Extraction \\
\hline $\mathrm{X} 1$ & 1.000 & .564 \\
\hline $\mathrm{X} 2$ & 1.000 & .568 \\
\hline $\mathrm{X} 3$ & 1.000 & .513 \\
\hline $\mathrm{X} 5$ & 1.000 & .624 \\
\hline $\mathrm{X} 6$ & 1.000 & .678 \\
\hline $\mathrm{X} 7$ & 1.000 & .693 \\
\hline $\mathrm{X} 8$ & 1.000 & .675 \\
\hline $\mathrm{X} 9$ & 1.000 & .573 \\
\hline $\mathrm{X} 10$ & 1.000 & .542 \\
\hline $\mathrm{X} 11$ & 1.000 & .516 \\
\hline $\mathrm{X} 12$ & 1.000 & .609 \\
\hline $\mathrm{X} 13$ & 1.000 & .638 \\
\hline $\mathrm{X} 14$ & 1.000 & .678 \\
\hline $\mathrm{X} 16$ & 1.000 & .554 \\
\hline $\mathrm{X} 17$ & 1.000 & .665 \\
\hline Extraction Method: Principal \\
Component Analysis. \\
\hline
\end{tabular}


Berdasarkan tabel di atas diperoleh bahwa 15 faktor yang ada mempunyai nilai Communalities yang besar > 0.5. Hal ini berarti bahwa 15 faktor yang digunakan memiliki hubungan yang kuat dengan faktor yang terbentuk. Langkah berikutnya pada tahap kedua ini adalah pemeriksaan terhadap Eigenvalue pada tabel Variance explained. Eigenvalue dari analisis factor pada tahap ini menunjukkan bahwa keseluruhan variabel yang dianalisis membentuk 4 komponen. Dapat dilihat pada tabel berikut ini:

\section{Tabel}

\section{Total Variance Explained}

\begin{tabular}{|c|c|c|c|c|c|c|}
\hline \multicolumn{7}{|c|}{ Total Variance Explained } \\
\hline \multirow{2}{*}{$\begin{array}{l}\text { Compo } \\
\text { nent }\end{array}$} & \multicolumn{3}{|c|}{ Initial Eigenvalues } & \multicolumn{3}{|c|}{ Extraction Sums of Squared Loadings } \\
\hline & Total & $\%$ of Variance & Cumulative $\%$ & Total & $\%$ of Variance & Cumulative $\%$ \\
\hline 1 & 4.133 & 27.551 & 27.551 & 4.133 & 27.551 & 27.551 \\
\hline 2 & 1.910 & 12.732 & 40.283 & 1.910 & 12.732 & 40.283 \\
\hline 3 & 1.561 & 10.404 & 50.687 & 1.561 & 10.404 & 50.687 \\
\hline 4 & 1.417 & 9.448 & 60.135 & 1.417 & 9.448 & 60.135 \\
\hline 5 & .945 & 6.297 & 66.433 & & & \\
\hline 6 & .788 & 5.252 & 71.685 & & & \\
\hline 7 & .738 & 4.917 & 76.602 & & & \\
\hline 8 & .620 & 4.134 & 80.736 & & & \\
\hline 9 & .583 & 3.886 & 84.622 & & & \\
\hline 10 & .565 & 3.765 & 88.388 & & & \\
\hline 11 & .458 & 3.051 & 91.438 & & & \\
\hline 12 & .417 & 2.781 & 94.219 & & & \\
\hline 13 & .381 & 2.537 & 96.756 & & & \\
\hline 14 & .292 & 1.949 & 98.705 & & & \\
\hline 15 & .194 & 1.295 & 100.000 & & & \\
\hline Extracti & Method: & Principal Compo & nent Analysis. & & & \\
\hline
\end{tabular}

Berdasarkan tabel di atas, terlihat bahwa 4 (empat) faktor yang terbentuk pada analisis tahap kedua ini. Hal ini menunjukkan besarnya persentase total yang mampu diterangkan oleh keragaman faktor-faktor yang terbentuk. Isi dari tabel tersebut juga terdapat nilai Eigenvalues dari tiap-tiap faktor yang terbentuk. Faktor 1 sebesar 4.133, faktor 2 sebesar 1.910, faktor 3 sebesar 1.561, faktor 4 sebesar 1.417. Hasil ini diperoleh berdasarkan nilai Eigenvaluenya, yaitu komponen dengan Eigenvalues $>1$.

Selain itu perlu juga dipastikan bahwa setiap variabel memiliki loading factor yayng memenuhi syarat yaitu > 0.5. Variabel dengan loading factor inilah yang kemudian dianggap valid untuk menjadi pembentuk suatu faktor. Untuk mengetahui hal tersebut, maka perlu ditelusuri melalui tabel Rotated Component Matries berikut ini:

\section{Tabel}




\section{Rotated Component Matries ${ }^{\mathrm{a}}$}

\begin{tabular}{|c|c|c|c|c|}
\hline \multicolumn{5}{|c|}{ Component Matrix $^{a}$} \\
\hline & \multicolumn{4}{|c|}{ Component } \\
\hline & 1 & 2 & 3 & 4 \\
\hline $\mathrm{X} 1$ & & .556 & & \\
\hline $\mathrm{X} 2$ & & 679 & & \\
\hline $\mathrm{X} 3$ & & & .595 & \\
\hline X5 & & & .535 & \\
\hline X6 & & & .514 & \\
\hline $\mathrm{X} 7$ & & & .503 & \\
\hline $\mathrm{X} 8$ & .602 & & & \\
\hline X9 & & & & .671 \\
\hline $\mathrm{X} 10$ & .685 & & & \\
\hline $\mathrm{X} 11$ & .537 & & & \\
\hline $\mathrm{X} 12$ & & & & .545 \\
\hline $\mathrm{X} 13$ & .514 & & & \\
\hline $\mathrm{X} 14$ & .546 & & & \\
\hline $\mathrm{X} 16$ & & & .657 & \\
\hline $\mathrm{X} 17$ & .535 & & & \\
\hline
\end{tabular}

Diketahui dari tabel di atas, ada 4 faktor yang terbentuk yang mempunyai faktor pendukung dengan nilai loading factor $>0.5$. Loading factor dari variabel tersebut mencerminkan korelasi sederhana antara variabel dengan faktor. Jadi semakin ttinggi nilai loading factornya berarti semakin erat hunungan variabel dengan faktor yang terbentuk.

Hasil penelitian dan analisis faktor yang dilakukan menunjukan ada 4 faktor terbentuk, serta setiap indikator mempunyai peranan pada setiap faktor terbentuk yang terdiri dari 15 indikator sebagai faktor menentukan keputusan konsumen menggunakan jasa Bengkel Mobil "Sinar Karya" di Kota Palu. Untuk lebih jelasnya pembahasan setiap indikator penelitian sesuai dengan faktor yang terbentuk dan mempunyai peranan paling besar dari indikator lainnya.

\section{KESIMPULAN DAN SARAN}

1. Berdasarkan hasil penelitian dilapangan diperoleh beberapa kesimpulan dalam penelitian ini sebagai berikut: (1) Hasil analisis faktor yang telah dilakukan dalam penelitian ini, terdapat 4 (empat) faktor yang dipertimbangkan konsumen dalam menggunakan jasa Bengkel Mobil "Sinar Karya" di Kota Palu. (2) Faktor people dan pelayanan terdiri atas 6 indikator yaitu, $\left(\mathrm{X}_{8}\right)$ menyambut ketika servis, $\left(\mathrm{X}_{10}\right)$ pelayanan karyawan bengkel yang sopan dan ramah, $\left(\mathrm{X}_{11}\right)$ pelayanan karyawan bengkel yang cepat dan 
tepat, $\left(\mathrm{X}_{13}\right)$ kesediaan melayani kembali pasca servis, $\left(\mathrm{X}_{14}\right)$ mendiskusikan kerusakan mobil dan $\left(\mathrm{X}_{17}\right)$ kepuasan setelah menggunakan jasa. (3) Faktor tempat (place) terdiri atas 2 indikator yaitu, $\left(\mathrm{X}_{1}\right)$ bengkel sudah dikenal dan $\left(\mathrm{X}_{2}\right)$ lokasi benkel mudah dijangkau. (4) Faktor hubungan kedekatan terdiri atas 2 indikator yaitu, $\left(\mathrm{X}_{9}\right)$ hubungan baik dengan pemilik karyawan bengkel dan $\left(\mathrm{X}_{12}\right)$ mendengar saran dari teman. (5) Faktor karakteristik terdiri atas 5 indikator yaitu yaitu, $\left(\mathrm{X}_{3}\right)$ peralatan bengkel yang lengkap, $\left(\mathrm{X}_{5}\right)$ pilihan cat bervariasi dan sesuai pesanan, $\left(\mathrm{X}_{6}\right)$ menggunakan system kendali dengan teknologi IT, $\left(\mathrm{X}_{7}\right)$ biaya service terjangkau dan $\left(\mathrm{X}_{16}\right)$ dapat melakukan modifikasi sesuai dengan pesanan pelanggan.

2. Berdasarkan kesimplan di atass, dapat direkomendasikan beberapa saran-saran sebagai berikut: (1) Disaran kepada pihak pemilik Bengkel Mobil "Sinar Karya" agasr selalu menjaga kualitas pelayanan yang ada, karna dengan adanya kulitas pelayanan yang baik tentunya akan membuat konsumen merasa puas dan nyaman. (2) Agar mempertahankan faktor-faktor yang lain dan selalu memprioritaskan terhadap kepuasan konsumen. Sehingga, konsumen loyal dan tidak berpindah-pindah. (3) Di harapka kepada pemilik bengkel untuk selalu kreatif dan inovatif dalam mempertahankan apa yang telah dicapai. (4) Diharapkan kepada pemilik dan karyawan bengkel untuk selalu menjaga kebersihan bengkel serta senantiasa menggunakan evaluasi kinerja.

\section{REFERENSI}

Hasan, Ali. 2013. Marketing dan Kasus-Kasus Pilihan. Yogyakarta: CAPS (Center For Academic Publishing Service).

Kotler, Philip, dan Kevin Lane Keller. 2009. Manajemen Pemasaran, Jilid 1 Edisi Ketiga Belas, Terjemahan Bob Sabran, MM. Jakarta: Penerbit Erlangga.

Kotler, Philip, dan Kevin Lane Keller. 2009. Manajemen Pemasaran, Jilid 2 Edisi Ketiga Belas, Terjemahan Bob Sabran, MM. Jakarta: Penerbit Erlangga.

Malhotra, Naresh K, 2005. Riset Pemasaran: Pendekatan Terapan (Edisi Keempat, Jilid 1). Jakarta: PT Indeks. Jurnal Ilmu dan Riset Manajemen, Vol 6 No. 11.

Mursid, D. M, 2010. Manajemen Pemasaran. Jakarta: Bumi Aksara.

Sugiyono, 2015. Metode Penelitian Kombinasi (Mixed Methods), Cetakan Ke-7. Bandung: Alfabeta.

Sumarwan, Ujang, 2011. Perilaku Konsumen Teori dan Penerapannya dalam Pemasaran, Edisi Kedua. Bogor: Ghalia Indonesia.

Tjiptono, Fandy, 2011. Pemasaran Jasa. Malang: Bayumedia.

Tjiptono, Fandy, 2014. Pemasaran Jasa. Jakarta: Gramedia Cawang.

Umar, Husein. 2013. Metode Penelitian Untuk Skripsi dan Tesis Bisnis.Jakarta: PT. Raja Grafindo Persada.

Widiyanto, 2012 Metodelogi Penelitian. Semarang: BP Udip. 